\title{
Quality promotion and capacity development - could they come to the aid of weary South African academics?
}

\author{
L G Boyd* \& J W Fresen
}

Independent QA consultant \& University of Pretoria

\begin{abstract}
Whilst research on policy implementation concludes that "the principles of equity and quality have been steadily internalised by institutions" (CHE 2003a), there has been a great deal of sometimes passionate dissent about how quality improvement should be implemented. In the South African context, stress and anxiety have developed within the higher education sector since the Higher Education Act of 1997. Quality improvement initiatives, like the adoption of ICTs or other systems, often fail for various reasons. Many difficulties arise due to the lack of trust and ownership of the system, which can be addressed by effective training, change management and implementation strategies. We contend that there is an immediate and urgent need for comprehensive quality promotion and capacity development programmes on a voluntary basis to support overburdened and quality-weary South African academics. Such initiatives would empower them to implement and assume responsibility for their own accountable quality assurance practices.
\end{abstract}

\section{INTRODUCTION}

Let's face it: It's not difficult for quality improvement initiatives to acquire a bad name. Our collective experience is littered with stories of quality initiatives which have yielded questionable benefits, and in some cases have been dismissed as a complete waste of time and money. Recent critics in the UK claim that external Quality Assurance has "invaded the life of academics, created significant extra workloads, and impacted negatively on the quality of student experience in that academics had less time available for their core business of teaching and research" (Stephenson 2003:3). Stephenson (2003:3) cites Newton's findings that in the UK "preparations for external assessment aimed specifically to mask reality from the gaze of external assessors", and that "many academics have grown increasingly sceptical of, and resistant to, the 'quality industry' and the "quality burden'".

Whilst research on policy implementation concludes that "the principles of equity and quality have been steadily internalised by institutions" (CHE 2003a), there has been a great deal of sometimes passionate dissent about how quality improvement should be implemented. The road so far has been described as 
"tumultuous" (Van der Westhuizen 2000:60), and continues to be so. In the South African context, there is also "considerable stress, strain and anxiety within higher education", and "the system, institutions and actors are at the limits of their capacities to absorb in terms of policy changes" (CHE 2003b online).

Difficulties in implementation are not uncommon in any quality improvement system, be it departmental, institutional or national. The term "Quality" itself is enigmatic: "Quality" terminology, such as Quality Assurance, Quality Management and Quality Control, is almost always subject to different interpretations. Quality is not easy to define, or even to know whether and how it exists. However, you know it when you see it or experience it, and you know when it is absent (Pirsig 1976).

When implementing quality management systems, it is common to experience a chasm, which develops all too quickly when practitioners are forced to bow to the demands of external auditors, and then once the auditors leave, carry on with "business as usual". The size of this chasm is proportional to the perceived realism or practicality of the external requirements. If the external requirements have not been well interpreted or explained, or if they are not readily "digestible" or applicable, then the chasm gapes to the extent that impression management, game playing and tick box mentality take over.

ISO9000 experience in the UK has shown that external auditors can sometimes be too quick to re-inforce destructive game playing. In one memorable incident the auditor wanted to record in an official audit report that the photocopying paper was being stored in a box without a lid. Another perception we found at the Ed-Media conference in Denver in 2002 was that "they send auditors in and they pick around and find fault with the way you file things!" (name withheld).

So, no wonder Quality often suffers from adverse perceptions. Yet there are few practitioners who would admit to a lack of interest in trying to improve what they do, either individually or as contributing members of their departments or institutions. It's part of the professional pride that most educators have. They instinctively want to improve their practice, especially if they can perceive the direct results it has for them and their students.

\section{SAQA AND THE NQF}

A SAQA document describes the National Qualifications Framework (NQF) as follows: "The National Qualifications Framework is essentially a quality assurance system with the development and registration of standards and qualifications as the first important step in implementing a quality education and training system in South Africa" (SAQA 2001b:199). Major concerns have since been raised about the complexity, resource-intensiveness, and sustainability of the NQF (SAQA 2002).

In April 2002 the report of a Study Team on the implementation of the NQF was released. Amongst other things it concluded that "the architecture of the NQF, 
embracing policies, regulations, procedures, structures and language, is experienced as unduly complex, confusing, time-consuming and unsustainable" (SAQA 2002:1). Respondents in the study strongly criticised the proliferation of bodies responsible for standards setting and quality assurance. They also identified an absence of strategic leadership and co-ordination, as well as a failure to give expertise its due (SAQA 2002).

The report confirmed the depth of feeling about the implementation of the NQF: "As the NQF design has rolled out, an interesting polarity has developed among those involved in the process. Everyone supports the NQF and its objectives. Almost no one thinks it is being done entirely correctly. Some have felt 'so alienated by the manner of its implementation that they are close to abandoning it" " (SAQA 2002:131).

Historically SAQA documents tended to be verbose, unwieldy, repetitive and full of confusing terminology. For example, the following paragraph needs to be read and re-read in search of understanding of the point being made:

The quality of the product or outcome is the primary responsibility of National Standard Bodies (NSBs) and their Standard Generating Bodies (SGBs). The quality of inputs and process is the primary responsibility of Education and Training Quality Assurance bodies (ETQAs) and providers of learning. The quality of products or outcomes will have a bearing on the quality of the inputs and processes as they lay a basis for the nature of inputs and processes required to achieve the products or outcomes. Likewise, the quality of the inputs and processes will have a bearing on the quality of the products or outcomes. It is in the quality management and assurance of the inputs and processes that the appropriateness of the design and the personal and national social-political and economic relevance of an outcome can be determined (SAQA 2001a:187).

The paragraph above also appears to remove much of the responsibility from the providers of learning and place it in the hands of the education authorities. Since that time, the HEQC has been careful to redefine its position and make clear its belief that responsibility for QA lies first and foremost with higher education institutions (HEIs) themselves (CHE 2003c).

The Department of Education (DoE) and Department of Labour (DoL) formed a joint Task Team to respond to the Study Team report. They produced a Consultative Document, which accepted the Study Team's overall analysis and most of its more specific proposals (SAQA 2003). One of the proposals accepted is that a single set of bodies should be responsible for both standard setting and quality assurance. The Consultative Document proposed "three powerful new bodies, to be known as Qualifications and Quality Assurance Councils (QCs) to replace the existing NSB/SGB/ETQA structure" (SAQA 2003:26).

It remains to be seen whether these proposals will be implemented, but at least 
they represent an acknowledgement at the highest level of the concerns of learning providers that they have been faced with unduly complex and confusing demands.

\section{THE EMERGING DEBATE IN HIGHER EDUCATION}

Hay and Herselman (2001) conducted a survey amongst academics and reported that most of the respondents ( 70,0 percent) felt uncertain about policy requirements regarding the registration of programmes with SAQA. "Despite all the noble intentions of government's policy initiatives and institutional quality assurance systems, quality is not welcomed, neither understood by all" (Hay \& Herselman 2001:32). The same authors found from the literature that where there are discrepancies between stakeholders of institutions, where a common vision for quality is not shared, nor ownership of the quality assurance system accepted, then little progress will be made, and more seriously, conflict will be inevitable.

Comments from the floor during a symposium held on Globalisation and Quality Assurance at the University of Pretoria in August 2002 illustrated further the depth of feelings amongst academics, regarding QA issues in higher education:

- "Where is provision in this huge structure to protect the creators of knowledge and to promote the research outputs of academics?"

- "The terms 'academic' and 'scientific' seem to have been lost — they don't fit into the vocabulary of the quality assurance scene."

- "We just mixed it up and expect academics to do everything."

- "We haven't provided the administrative support functions to meet the demands of SAQA."

- "We should focus on what a university should be doing, rather than on what they must be doing."

- "We should focus on knowledge production, not on the number of degrees we give out."

- "Quantity seems to have overtaken Quality."

- "It is astonishing how accommodating South Africa's liberal universities have been of this government, when they spoke out so forcibly against the previous government."

- "We've been mesmerised — when and from where will the point of resistance come?"

The plea on behalf of academics is also evident in international education circles, as described by Hammond and Morris (2002): "The unintended consequences of the accountability demands of the imposed standardised curriculums, so loved by educational bureaucrats world-wide, are killing teacher enthusiasm forcing creative teachers to leave the classroom" (online).

The same authors refer to the demands on teachers which prevent them from giving their full attention to their core business: "Trying to cope with the demands of unwieldy imposed curriculums (no matter how much they are 'benchmarked', 
'slimmed down' or 'stocktaked') has diverted teachers from focusing on teaching and learning strategies to achieve quality learning" (online).

Maharey (2000) emphasises the importance of considering the needs of all stakeholders involved in the education process: "We have to go beyond managerialism to a new partnership between governors, managers and teachers with a clear focus on the needs of all stakeholders" (online).

The HEQC has signalled its sensitivity to these issues in the way it has chosen to design a specifically South African QA system: "It has been a massive challenge to rigorously and sensitively conceptualise, plan and begin to implement a quality assurance system that is effective and efficient, financially prudent, does not retard responsiveness on the part of providers and is simultaneously developmental and improvement oriented but also ensures minimum standards and protection for students and the public" (CHE 2003b:online).

\section{BALANCING EXTERNAL CONTROL AND SELF-EVALUATION}

Clarence Beeby, a prominent New Zealand educationist in the 1960s, proposed a model in his book on the quality of education in developing countries (Beeby 1966). His model appears to be highly relevant almost 40 years later.

Beeby's model analyses education systems and identifies four developmental stages, based on the level of education and training of the teachers. He found that the degree of external control required in schools is inversely proportional to the four levels of educational growth. That is, the higher the level of development, the lower is the degree of external control required.

Table 1 summarises Beeby's model and gives more details of the levels of educational growth and the corresponding degree of external control required.

Table 1: Degree of external control associated with Beeby's four levels of educational growth (Summarised from Beeby 1966)

\begin{tabular}{|c|c|c|}
\hline & Teachers & Degree of external control \\
\hline I & Ill-educated, untrained & $\begin{array}{l}\text { - confused and inefficiently formal } \\
\text { - there is no alternative for the system as a } \\
\text { whole but to impose more form and control } \\
\text { - such under-prepared teachers welcome di- } \\
\text { rection - the stricter and tighter the control, } \\
\text { the safer they feel }\end{array}$ \\
\hline II & Ill-educated, trained & $\begin{array}{l}\text { - highly organized at a routine level } \\
\text { - detailed and rigid official syllabus } \\
\text { - restricted number of narrow textbooks } \\
\text { - tight external examinations } \\
\text { - rigorous system of inspection }\end{array}$ \\
\hline
\end{tabular}




\begin{tabular}{|c|c|c|}
\hline & Teachers & Degree of external control \\
\hline III & Better-educated, trained & $\begin{array}{l}\text { - external controls, while formidable, are less } \\
\text { detailed than at stage II } \\
\text { - official syllabus remains } \\
\text { - final examination set by educational authority }\end{array}$ \\
\hline IV & Well-educated, well-trained & $\begin{array}{l}\text { - external controls are relaxed } \\
\text { - external examinations either disappear or } \\
\text { shrink in importance } \\
\text { - inspection shades into professional co-opera- } \\
\text { tion }\end{array}$ \\
\hline
\end{tabular}

Two important conclusions from the Beeby model can be applied to our current situation in South Africa. These are:

- the more educated and experienced educators are, the less external control is required, or in fact, desired, once their ability to assure their own quality has been established;

- reformers need to be sensitive to where groups of educators may lie on the continuum of educational growth, so as to optimise the chances of success and minimise alienation.

The foreword in Baijnath, Maimela and Singh (2001) describes this dilemma exactly: "A balance has to be found between the role of external regulatory and evaluative agencies on the one hand and that of self-evaluation, continuous improvement and quality promotion within institutions on the other. There is a real danger of over-regulation and bureaucratization to the point that the QA process breeds a compliance culture and therefore becomes less than it might be" (Baijnath et al 2001:vii).

Vroeijenstijn (1995) famously described it as navigating between two treacherous traps: Scylla, a nymph-turned-monster with six heads and Charybdis, a frightful whirlpool churning and disgorging the sea water around him (Bulfinch 1968). In the words of Vroeijenstijn (1995:xiv): "Being responsible for a system of External Quality Assurance (EQA) is like navigating between Scylla and Charybdis. Is it possible to reconcile the irreconcilable? Aiming only at improvement, the system will be shipwrecked against the Scylla because the outside stakeholders will ask for accountability and design their own EQA system. Overemphasizing accountability, the system will disappear in the Charybdis, because improvement will be hindered or even made impossible."

It can be argued that internal self-improvement or self-regulation, and external accountability are not mutually exclusive opposites, but both fundamental component parts of a functioning institutional quality assurance system. Both 
components need to be present in order for the system to be effective. In today's landscape, accountability requirements will not go away. However the initiative for internal improvement and quality assurance should always come from within, and be used to "balance" accountability requirements from outside. The more effective internal QA arrangements there are, the less probing the external monitoring need be.

\section{REASONS FOR FAILURE OF QUALITY IMPROVEMENT INITIATIVES}

Vroeijenstijn (2001:149) presented a series of basic conditions for an [external] QA system to be successful. These are:

- A QA system should be as simple and efficient as possible.

- It should be trusted by all stakeholders.

- It should offer the possibility for the government to fulfil its responsibility for quality assurance towards parliament and the public.

- It should be cost effective.

- It should be recognised internationally.

From our experience, we suggest the following as a non-exhaustive list of the reasons why quality improvement initiatives fail, from a user point of view. Incidentally, the list applies equally to the failure or lack of take-up of information and communication technology (ICT) systems.

The users of the proposed initiative or system:

- don't perceive that it will yield any benefit for themselves or their "customers" (those who receive their services or products)

- can't make sense of it or are confused by its jargon and complexity

- can't understand its purpose

- feel that they have been coerced into it

- don't think that it applies to them

- don't perceive that they have a problem situation which merits improvement

- had inappropriate or unrealistic expectations of the system, which weren't fulfilled.

Many of these issues relate to establishing trust and ownership of the system, and can be addressed by effective training, change management and implementation techniques. The process of implementation is to marry the proposed system with the people who are going to use it, so that it becomes a part of their everyday work. Effective training and change management techniques enable the recipients to "have a voice" about the system, air their concerns and issues, feel that they are contributing to the change, and learn how to effectively interact with the system. By being involved, they can progress through the cycle of commitment. This provides no guarantee that the proposed system will be eventually successful and 
yield its intended benefits; but the chances thereof will be dramatically increased. A new system rarely succeeds purely by its just being available, or at the other extreme, just by being mandatory.

\section{QUALITY PROMOTION AND CAPACITY DEVELOPMENT}

It is apparent that the HEQC is mindful of the need for support aimed at assisting academics and institutions through the process of change and adoption of QA initiatives. The HEQC website (http://www.che.org.za/heqc cq/capacity.php) makes a distinction between "quality promotion" (awareness of the need for change), and "capacity development" (enhancing skills to achieve specific results).

There have been several initiatives aimed at institutional capacity development. Examples of which we are aware are the SAUVCA Quality Promotion Unit which was closed down in 1999, the QA Managers Forums convened by SAUVCA and the HEQC, and some activities driven by regional higher education (HE) associations such as FOTIM.

Emphasis within the HEQC has thus far been placed on the Improving Teaching and Learning project to develop good practice criteria and guidelines on a range of issues. Attention has also been given to the training of audit chairs and panel members, programme evaluators and HEQC staff in readiness for the first audit cycle. In addition, there has been a programme of one day visits by the HEQC to all public HE institutions and a sample of private institutions to contextualise work of the HEQC and internal quality management systems (CHE 2003a). The HEQC is utilising the first cycle of audits, planned to commence in late 2004, to "facilitate capacity development and improvement programmes by the HEQC and other roleplayers" (CHE 2003c:online).

The first cycle of audits is planned to extend until 2009, five years hence. Our contention is that there is an immediate real requirement for a comprehensive quality promotion and capacity building programme to support and not burden the already quality-weary South African academic. This type of capacity building should consist firstly of very simple non-threatening and supportive initiatives concerning how to improve "the way one does things". Secondly, it needs to demystify and interpret quality assurance theory and practice in a way which engenders ownership and motivation to develop internal QA systems. Finally, it should assist in setting the scene for external audits. Our argument is that academics need a way of understanding practical self-improvement issues now, which they can deploy simply for themselves. O'Connell expressed it in his keynote address at the 5th CHE Consultative Conference in November 2003: "... management theory suggests that when major change is contemplated we must do our best to bring the critical mass of the people along. They should understand and accept why this is happening and that a successful outcome offers huge benefits that will contribute greatly to the common good". He goes on to say that 
"one must seek champions who will go out and preach the good news and who will expertly manage the changes, consistently increasing the confidence of those who must implement the changes and those who will be impacted upon by them" (O'Connell 2003:online).

The type of capacity development we are advocating is aimed at directly supporting academics and departments within their institutions. It should complement the existing capacity development initiatives of the HEQC and other bodies. It should be available to public and private providers alike. It should be available on a voluntary basis, as a result of expressed needs, instead of having to respond to centrally specified criteria. It should be very simple and digestible in its approach, but tailored to the level of education and experience of the audience. It should share best practice from those who have made good progress, and coach those institutions who need it, based on their own perceived improvement objectives. One way of operationalising this ideal would be to have a web-based discussion forum for HEIs to exchange experiences and share examples of successful case studies. This would contribute to demystifying the benefits of quality improvement initiatives and promoting the commitment of academics.

Such quality promotion and capacity development initiatives will be time and resource intensive. The suggestions in this article will hopefully contribute to the existing strategic plans of the Capacity Development and Quality Promotion unit of the HEQC.

\section{CONCLUSION}

It seems that "quality assurance" and associated terms are in danger of becoming "dirty words" in (South African) higher education circles, unless a great deal more emphasis is placed on capacity building initiatives aimed directly at individual institutions and academics. These initiatives should empower institutions to voluntarily develop their own internal quality assurance systems, in a supportive and non-threatening manner. Initiatives should be presented in a simple and easy to digest fashion, in a way that is meaningful and helpful to South African academics. There are few remaining chances to capture the buy-in of hard-pressed academics, before damaging de-motivation, minimal compliance and impression management become the realities which other countries appear to be experiencing.

Like A A Milne's Winne-the-Pooh, many academics feel that they have become overwhelmed by outside pressures and demands: "Here is Edward Bear, coming downstairs, now, bump, bump, bump, on the back of his head behind Christopher Robin. It is as far as he knows the only way of coming downstairs, but somewhere he feels there is another way, if only he could stop for a moment and think of it" (A A Milne, quoted by Hammond \& Morris 2002).

As educators we seem to be forever bumping our heads against bureaucracy, although we know there should be a better way of assuring the quality of the learning opportunities we offer our students. 
Let us provide space for academics to be able to perform their core functions as providers and disseminators of knowledge resulting from scientific research. Let us provide appropriate training and support to empower them to implement, and assume responsibility for, their own accountable quality assurance practices.

\section{REFERENCES}

Baijnath, N., Maimela, S. \& Singh, P (eds) 2001. Quality assurance in open and distance learning. University of South Africa and Technikon South Africa.

Beeby, C. E. 1966. The quality of education in developing countries. Cambridge Mass: Harvard University Press.

Bulfinch, T. 1968. Bulfinch's mythology. Middlesex: Hamlyn House.

CHE 2003a. The transformation of higher education in South Africa: how much have we achieved? Council for Higher Education. Available online at: http://www.che.ac.za/ documents/d000052/CHE_CCRESEARCH_REPORT_Nov27_final.pdf

CHE 2003b. CHE Annual Report 2002-2003. Council for Higher Education. Available online at: http://www.che.ac.za/documents/d000046/CHE_Annual_Report_2003b.pdf.

CHE 2003c. Higher education quality committee. Proposed criteria for the HEQC's first cycle of audits 2004-2009. Council for Higher Education. Available online at: http:// www.che.ac.za/documents/d000026/Audit_Criteria_March2003.pdf.

Hammond, B. \& Morris, W. 2002. The challenge for the next decade. Leading and learning for the 21st century, 1(4). Available online at http:/www.leading-learning.co.nz/newsletters/ vol01-no04-2002.html.

Hay, H. R. \& Herselman, M. E. 2001. An investigation into the perceptions of academic staff on quality assurance in teaching and learning at selected South African universities. South African Journal of Higher Education 15(3):131 - 141.

Maharey, S. 2000. Innovative, strong and responsive institutions: developing a framework for success. Available online at: http://www.apnz.ac.nz/conferences/past_conferences/2000/ main_2000_maharey.htm.

O'Connell, B. 2003. Keynote address at the 5th CHE Consultative Conference. Benoni, 12 November 2003. Available online at: http://www.che.ac.za/documents/d000052/KeyNote_CC5_Speech_12_11_03.pdf.

Pirsig, R. 1976. Zen and the art of motorcycle maintenance. London: Corgi.

SAQA 2001a. The National Qualifications Framework and Quality Assurance, Appendix 1, in Baijnath, N., Maimela, S. \& Singh, P. (eds) Quality assurance in open and distance learning. University of South Africa and Technikon South Africa.

SAQA 2001b. Standards setting and the National Qualifications Framework, Appendix 2, in Baijnath, N., Maimela, S. \& Singh, P. (eds) Quality assurance in open and distance learning. University of South Africa and Technikon South Africa.

SAQA 2002. Report of the Study Team on the implementation of the National Qualifications Framework. Executive Summary. Pretoria: Department of Education, Department of Labour. Available online at: http://www.saqa.org.za/saqa.asp?main=publications/publicationscover.htm\&menu=pubs

SAQA 2003. An interdependent National Qualifications Framework system: a consultative document. Available online at: http://www.saqa.org.za/docs/reports/nqf0307a.pdf.

Stephenson, S. 2003. Saving quality from quality assurance. Paper presented at the 15 th International Conference on Assessing Quality in Higher Education. Cape Town, 14 - 16 July 2003. 
Van der Westhuizen, L. 2000. Policy development of quality assurance: a critical perspective on past and future issues. South African Journal of Higher Education 14(2):56 - 61.

Vroeijenstijn, T. 1995. Improvement and accountability: navigating between Scylla and Charybdis. Guide for external quality assessment in higher education. London: Jessica Kingsley.

Vroeijenstijn, T. 2001. An outsider's view on the development of quality assurance in South African higher education, in Baijnath, N., Maimela, S. \& Singh, P. (eds) Quality assurance in open and distance learning. University of South Africa and Technikon South Africa. 